\title{
EFFICIENCY OF TIDAL TURBINE FARMS
}

\author{
Colin Christian ${ }^{1} \&$ Ross Vennel $^{2}$
}

The paper investigates the efficiency of tidal turbine farms and looks at the effects of various parameters. Numerical modelling and analytic solutions are used. The two methods are compared and differences highlighted. Some loose guidelines are included.

Keywords: Turbine farms; Efficiency;

\section{INTRODUCTION}

The migration towards clean renewable energy has driven a renewed interest in producing power from waves and tidal currents. The rise in oil prices over the last decade has encouraged this move as the renewables become more economically viable. This paper concentrates on tidal power generated by a group of submerged turbines colloquially known as farms. Tidal power has the great advantage over other forms in that the tidal current may be accurately predicted over a long period of time. Aside from mechanical problems it is thus easy to predict the power output at any time in the future. Two major projects are in the project planning stage in New Zealand with a targeted generating capability of approximately $200 \mathrm{MW}$. These have been proposed for tidal channels close to coastlines.

Several manufacturers now have efficient devices under test in various parts of the world, but a viable farm has yet to be established. One of the problems in establishing a farm is that of predicting performance in a commercial environment. Single turbines in a tidal flow field behave as expected and the output may be predicted readily. The turbine rotor may be optimised to produce maximum power for a given flow speed. However each turbine produces a large wake and alters the surrounding flow field. There is a balance between trying to extract maximum power and having minimum effect on the flow field. This is complicated by the fact that most of these turbines have to generate power from the ebb and flood tide. Thus the turbine blades generally are a compromise to allow generation in both directions. Further the more power the turbine extracts the more it alters the flow. The change in flow field is important in relation to environmental effects, such as scour and sediment transport. A further question arises when more than one turbine is installed and that is where should the turbines be installed relative to each other?

Simple numerical flow models have been developed primarily to investigate the effect that a large farm might have on the stability of local coasts due to changes in the flow field. Basically the turbine is treated as a local head loss element in a finite element scheme. Initially a simple channel has been used as a test bed, but a prototype situation has also been looked at. By adjusting the head loss coefficients more or less power could be extracted. Essentially the turbine behaves as a blockage to the flow and the larger the head loss through the turbine the more effect it has on the flow. At the same time the velocity through the turbine is reduced. There is a trade off here between head loss and flowrate, but there will be an optimum level for efficient power extraction. It is observed that the flow seeks the path of least resistance and tends to flow around the turbine as power extraction is increased.

Adding additional turbines to a farm have a marked effect on the overall power production from the farm. It is found that a single turbine produces its rated power but as the effects of shadowing increase the output per unit decreases. This is as one would expect as the turbines in a group slow the flow field in a macro sense. This has many implications to the planning of a farm. Often a staged development is desirable from an economic point of view but this approach has implications of the tuning of the turbines.

The paper will present the numerical and analytical results for groups of turbines in various situations and compare and contrast the results. Guidelines for future work and turbine farm development are presented.

\section{Background}

The energy flux for a uniform flow with a velocity of $\mathrm{u}_{0}$ is

$$
P_{f}=1 / 2 \rho u_{0}^{3}
$$

\footnotetext{
1 Colin Christian Ltd, P O Box 25236, St Heliers Bay, Auckland 1740, New Zealand.

2 Ocean Physics Group, Department of Marine Science, University of Otago, Dunedin 9054, New Zealand. 
This has units of watts $/ \mathrm{m}^{2}$, so for a $20 \mathrm{~m}$ diameter turbine (area $314 \mathrm{~m}^{2}$ ) a flow of $2 \mathrm{~m} / \mathrm{s}$ the maximum instantaneous power would be $\sim 1.29 \mathrm{MW}$. That is from an energy flux of $4.1 \mathrm{~kW} / \mathrm{m}^{2}$. For a square area of $400 \mathrm{~m}^{2}$ the power is $1.64 \mathrm{MW}$. (note: this is for sea water density of $1025 \mathrm{~kg} / \mathrm{m}^{3}$ ).

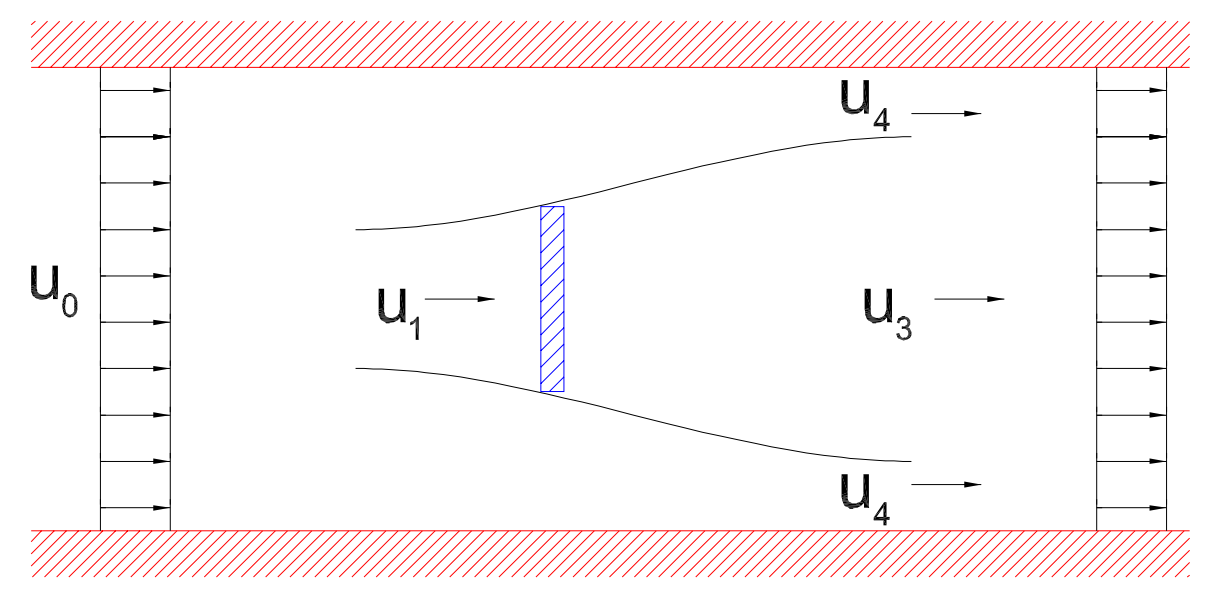

\section{Figure 1 Classical Turbine analysis}

Classical analysis of a propeller, by (Lanchester, 1915) and (Betz, 1920), indicate that the maximum power available would be $59 \%$ of that available in the free stream. This is $741.4 \mathrm{~kW}$ for the above example. This classical analysis made some assumptions concerning the pressure recover. This value occurred when $u_{1}=2 / 3 u_{0}$ and $u_{3}=1 / 3 u_{0}$, which are often used as starting values.

Another way of looking at this is that to remove $1 \mathrm{MW}$ from a flow of $2 \mathrm{~m} / \mathrm{s}$ then the turbine area needs to be $22.9 \mathrm{~m}$ in diameter equivalent. Note this includes the $59 \%$ factor.

Note with $u_{0}=2.5 \mathrm{~m} / \mathrm{s}$ the figures give an energy flux of $8.0 \mathrm{~kW} / \mathrm{m}^{2}$, and maximum of $3.3 \mathrm{MW}$ for the same turbine or $1.9 \mathrm{MW}$ after the $59 \%$. The analysis made some simplifying assumptions and ignored many important effects. It turns out that this result is over conservative and better performance may be achieved.

A number of authors have expanded the earlier work and a brief summary is as follows:

Garret and Cummins (Garrett \& Cummins, 2005) (GC05) analysed a turbine farm occupying a channel with a constant flow, they allow the turbines to affect the flow rate as the effective friction is increased due to the farm. They produced an expression for the maximum averagepotential power as

$$
\bar{P}_{\max }=0.22 \rho g \eta_{0} U_{0 U D}
$$

where $\eta_{0}$ is the amplitude of the head difference across the ends of the channel, and $U_{0 U D}$ is the amplitude of the tidal transport. Both of these are difficult to measure accurately in a realistic situation. Their later paper (Garret \& Cummins, 2007) (GC07) expands upon the earlier work and tunes the turbines by adjusting the downstream flow $u_{3}$ to be $1 / 3$ of the free stream velocity $u_{0}$. However it requires the turbines to stretch across the whole cross section and is for steady flow with no bottom friction.

Vennel's work (Vennel, 2010, 2011, 2012) (referred to as V10, V11, V12) expand on the Garret \& Cummins work to include the ideas in GC05 and GC07 and extend the work to cover cases where the turbines only occupy a fraction of the channel width. He also introduces the idea of tuning different rows of turbines to optimise the power produced.

The analysis described below is developed from the ideas in V12.

\section{Test Cases}

The characteristics of a stretch of water is considered to depend upon the dominant driving force for the flow. As will be seen later this characteristic is important in the design of a turbine farm. 
As a loose convention the site may be characterised as a tidal straight or a shallow channel, both of which occur in nature and there will be a complete set between the two extremes.

For wide deep tidal straight the inertial force dominates the flow mechanics and the bottom friction is generally small. Typical characteristics might be $100 \mathrm{~km}$ long, depth about $150 \mathrm{~m}$ and $25 \mathrm{~km}$ wide giving a cross sectional area of $3.8 \mathrm{~km}^{2}$. The undisturbed max velocity might be of the order of $1.1 \mathrm{~m} / \mathrm{s}$. A tidal straight typically occurs between large islands or between mainland and an island.

At the other end of the spectrum is the shallow channel where bottom friction is the dominant force. It is typically $30 \mathrm{~m}$ deep and about $3 \mathrm{~km}$ wide. The cross sectional area varies between 70,000 and $85,000 \mathrm{~m}^{2}$ at low and mid tides. Tidal range is between 2.5 for spring tide and 1.5 for neap tides. Shallow channels typically connect an ocean to a large estuary.

Three scenarios used as models for these examples are commonly used:

- Channel with fixed levels at either end - flow changes with total drag

- Channel with fixed flow - levels change as drag increases

- Channel with sea level change at one end and a closed lagoon at the other - flow and level at lagoon change as drag increases

The power produced in each case will be different. Clearly the assumptions made in the analysis are important.

\section{NUMERICAL MODELLING}

Three scenarios were modelled using a finite element 2D flow model. The aim of this work was to validate the method to be used for examining the effects of installing the turbines in a prototype situation.

The turbines were modelled as an energy loss device, with bidirectional flow and the head loss modelled as

$$
H=A Q^{n}+B
$$

The index $n$ was taken as 2 for this case and $A$ adjusted as required to tune the turbine to give specified output for a given flowrate. Note that for the finite element model $q$ (flow per unit width) is used. The turbines selected for the test were such that they loosely represented the Open Hydro units and would look to produce $1 \mathrm{MW}$ from each $20 \mathrm{~m}$ diameter unit. The characteristics of the turbine (Bedard, 2005) are shown below.

The figures for Open Hydro correspond reasonably well with the model adopted here. The turbines were tuned to produce approximately $1.5 \mathrm{MW}$ from a flow of $2 \mathrm{~m} / \mathrm{s}$ through the turbine blades by adjusting the size and $A$ value. The $15 \mathrm{~m}$ twin Open Hydro unit was rated at $1.5 \mathrm{MW}$ at 5 knots.

Three test cases have been constructed.

- $12 \mathrm{~km}$ long channel, $3 \mathrm{~km}$ wide, $30 \mathrm{~m}$ deep with one $20 \mathrm{~m}$ turbine. Boundary conditions were an inflow and a water level at the other end.

- $\quad 12 \mathrm{~km}$ long channel, $3 \mathrm{~km}$ wide, 30m deep with 20 turbines in two rows 6 turbine diameters apart, turbines spaced 3 diameters apart in each row. Same BC's as the previous case.

- $12 \mathrm{~km}$ channel, $3 \mathrm{~km}$ wide $30 \mathrm{~m}$ deep connecting a sea to a large estuary. Sea level is adjusted to produce an M2 tide of approximately $2.5 \mathrm{~m}$ in the channel. Estuary area is $32 \mathrm{~km}$ square. This produced maximum velocity close to $2.0 \mathrm{~m} / \mathrm{s}$.

Velocities in the simple channel tests were approximately $2 \mathrm{~m} / \mathrm{s}$.

The turbines in the channel models were tuned by adjusting the A parameter to produce the maximum power. The velocity through the turbine compared with the free stream velocity $\left(r_{l}=u_{l} / u_{0}\right)$ is plotted below against power produced. 


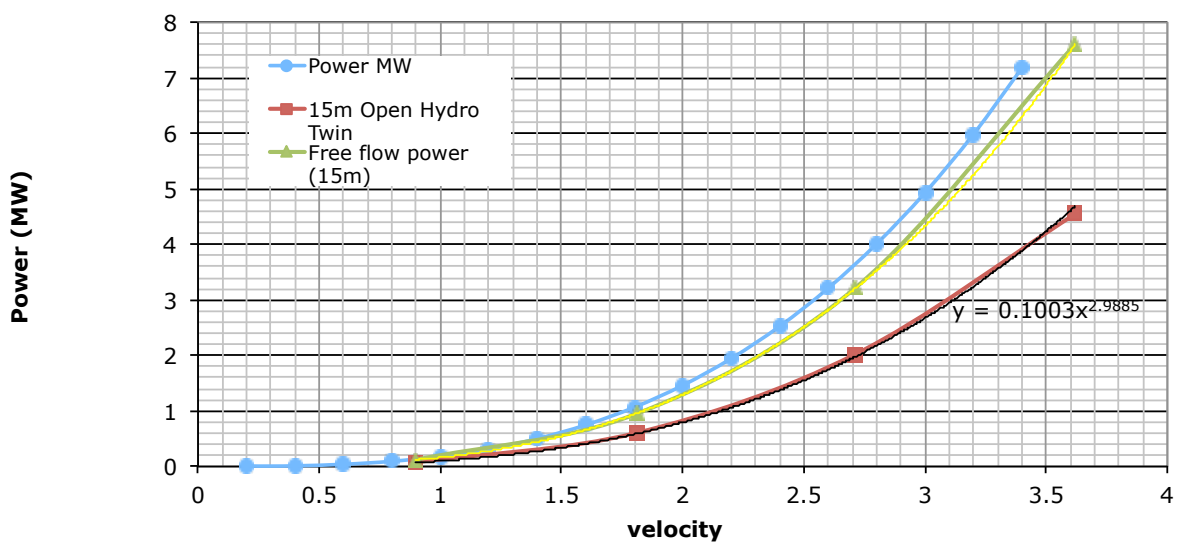

Figure 2 Turbine characteristics

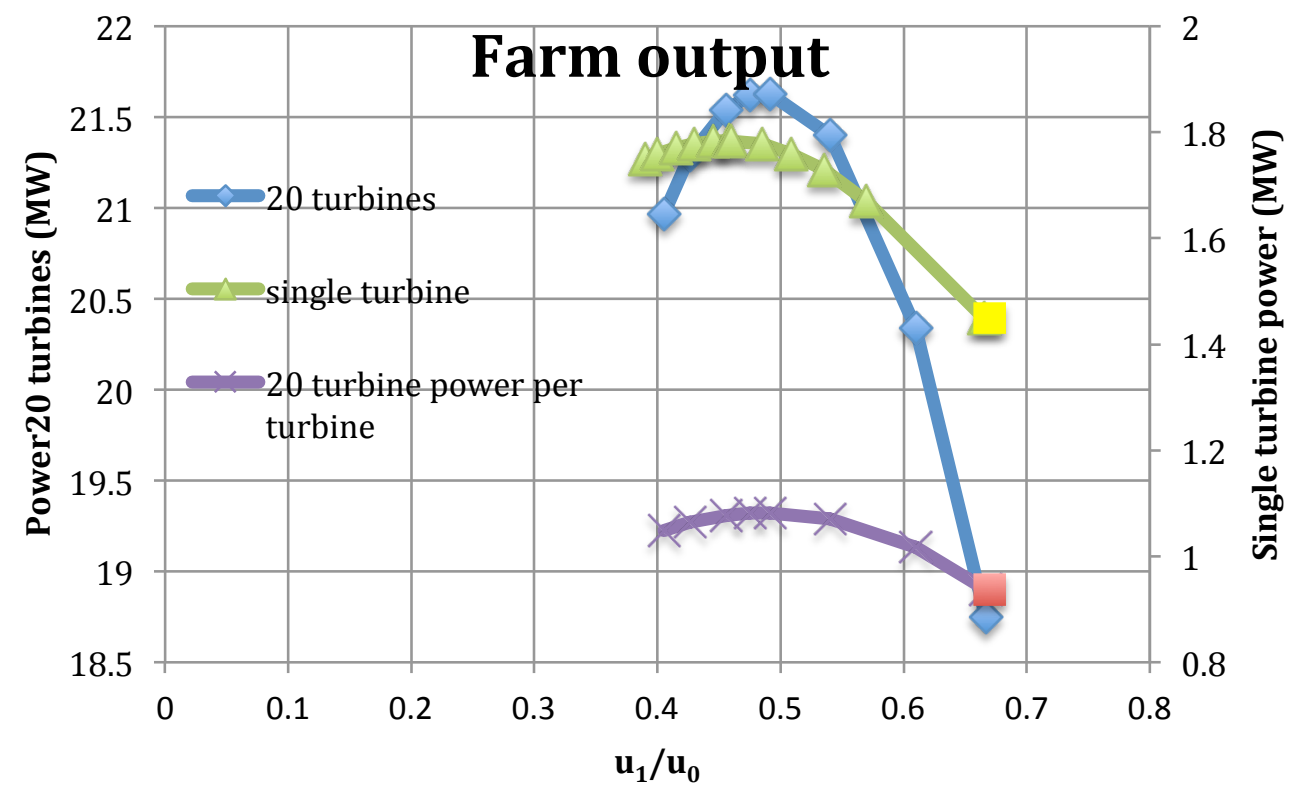

Figure 3 Power output for various scenarios

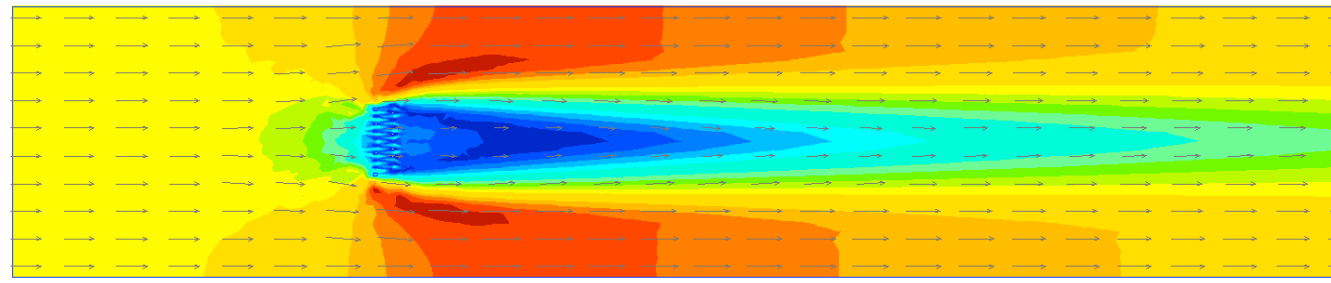

Figure 4 Flow field around 20 turbines in a channel 


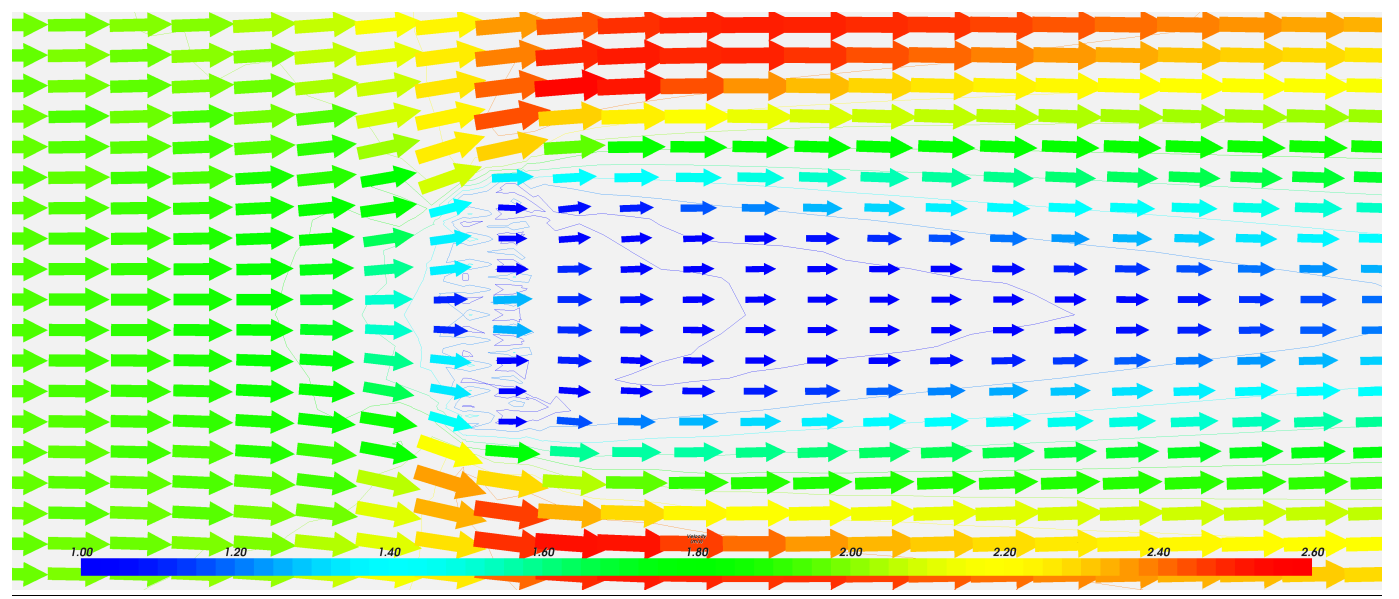

Figure 5 Flow detail around 20 turbines

The result from the tidal case gave similar results to the simple channel with a maximum power output of a little over $20 \mathrm{MW}$.

It is clear from the results that the single turbine is quite efficient in that the power is pretty much as specified, but when more turbines are added the power per turbine is reduced. The $\left(r_{I}=u_{I} / u_{0}\right)$ value is averaged over all the turbines for the case of the 20 turbines. The plots show that the maximum power is available for $r_{I}$ approximately 0.456-0.458. Setting $r_{I}$ to 0.67 , the Betz optimum, produced less power for both cases. The measurement of $r_{l}$ is problematic as there is flow around each turbine, which is faster that that through the turbine, as shown by the velocity plot above. The value of $r_{l}$ is closer to 0.725 if the gross effect of the 20 turbines is concerned.

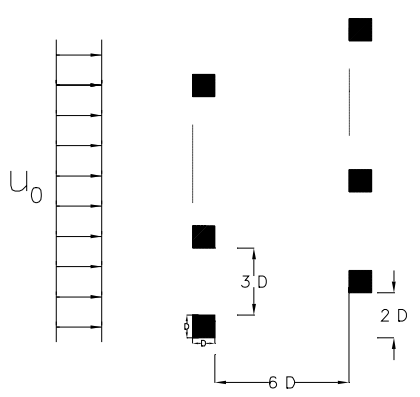

Figure 6 Turbine spacing for numerical mode

\section{ANALYTICAL ANALYSIS}

The following follows the analysis from (Vennell, 2012), for full details see the original paper. The governing equation to be solved is

$$
\frac{\partial U}{\partial t}=-\frac{g A}{L}\left[\eta_{2}-\eta_{1}\right]-\frac{A}{L}\left[\frac{L}{h} C_{d}+C_{F}\right] \frac{|U| U}{A^{2}}
$$

for a constant cross section channel

The equation may be non-dimensionalised as 


$$
\frac{\partial U^{\prime}}{\partial t^{\prime}}=\sin \left(t^{\prime}\right)-\frac{3 \pi}{8} \lambda_{\text {total }}\left|U^{\prime}\right| U^{\prime}
$$

variables are as follows:

$u \quad$ velocity $x$ direction

$A$ cross sectional area

$U \quad$ transport $=u(x, t) \cdot A(x)$

$t$ time

$t^{\prime}$ non dimensional time $=\omega \mathrm{t}$

$h^{\prime}$ non dimensional depth $=h / h_{0}$ ( 1 for constant cross section)

$A^{\prime}$ non dimensional area $=A / A_{0}$ ( 1 for constant cross section)

$g$ gravitational acceleration

$U^{\prime}$ non dimensional transport $U^{\prime}=U \frac{\omega L}{g \Delta A_{0}}=\frac{U}{U}$

$\Delta$ amplitude of difference in water level between ends of channel (driving head)

$\omega$ phase speed of the tide $(\mathrm{rad} / \mathrm{s})$

$\lambda \quad$ normalised friction coefficient, $\lambda_{\text {total }}=\hat{\alpha}\left[\frac{L}{h} C_{d}+\frac{C_{F}}{A_{F}^{\prime 2}}\right]$

$A_{F}^{\prime}$ non dimensional area of flow at the farm. (=1 for constant cross section)

$C_{D}$ drag coefficient for channel bed

$C_{F}$ drag coefficient for the farm based on channel cross section

$\hat{\alpha} \quad \frac{8 g \Delta}{3 \pi \omega^{2} L^{2}}$ Constant used on non-dimensionalisation

$\varepsilon \quad$ area of channel occupied by turbine farm

$r_{i}$ is the ratio of local velocity to free stream velocity, eg: $r_{I}=u_{I} / u_{0}$

There is an approximate solution to the above which is

$$
\begin{gathered}
U^{\prime}=U_{0} \sin \left(t^{\prime}-\phi_{u}\right) \\
U_{0}\left(\lambda_{\text {total }}\right)=\frac{\sqrt{2}}{\sqrt{\sqrt{4 \lambda^{2}+1}+1}} ; \tan \phi_{u}=\frac{1}{\lambda_{\text {total }}} U_{0}
\end{gathered}
$$

this is an approximation which has an error of approximately $4 \%$ due to the non-linear drag terms.

Now $\varepsilon$ is the amount of cross section taken up by the turbine farm. If the ratio $r_{3}$ is given then other ratios may be computed following the GC07 scheme:

$$
\begin{gathered}
r_{4}=\frac{1-r_{3}+\sqrt{\varepsilon-2 \varepsilon r_{3}+\left(1-\varepsilon+\varepsilon^{2}\right) r_{3}^{2}}}{1-\varepsilon} \\
r_{1}=\frac{r_{3}\left(r_{4}+r_{3}\right)}{r_{4}+2 r_{3}-1}
\end{gathered}
$$

and for a one row farm 


$$
C_{F}=\frac{\varepsilon}{2}\left(r_{4}^{2}-r_{3}^{2}\right)
$$

Taking a value of 0.7 for $\varepsilon$, and 0.0025 for $C_{d}$, the following figure shows how the dimensionless powers vary with $\lambda_{\text {total }}$. Note this is not a universal chart as there are some assumptions made such as the length of channel, depth and head difference between the ends. So a different chart emerges for each physical setup. The tidal straight and shallow channel provide extreme limits for the geometry.

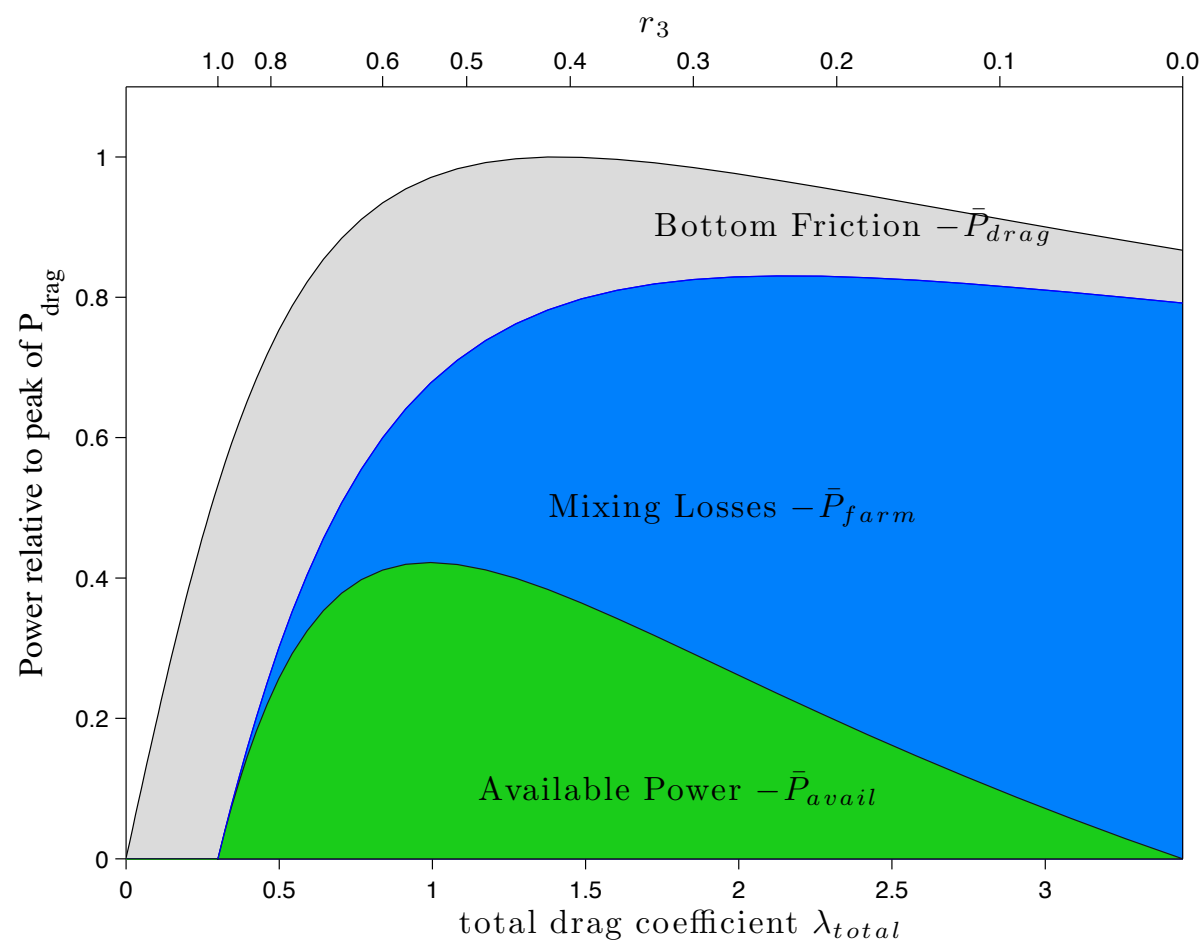

Figure 7 Turbine farm characteristics

The power lost by flow to drag within the channel averaged over a tidal cycle is may be derived as follows.

The drag force on the bottom of the channel is

$$
F=\rho C_{D} W L u_{0}^{2}
$$

so the Power lost due to friction is

$$
P=F u_{0}=\rho C_{D} W L u_{0}^{3}=\rho C_{D} \frac{A}{h} L u_{0}^{3}
$$

now introduce $\lambda$ and make $C_{D}$ dimensionless by:

$$
\begin{aligned}
& C_{D}=\frac{\lambda h}{\hat{\alpha} L} \quad: \quad u=\frac{U}{A}=\frac{U^{\prime} U_{I}}{A}: U_{I}=\frac{g \Delta A}{\omega L} \\
& P=\rho \lambda \frac{h}{L} \frac{3 \pi \omega^{2} L^{2}}{8 g \Delta} A\left(\frac{U^{\prime} g \Delta A}{\omega L A}\right)^{3}
\end{aligned}
$$


and then normalise by dividing by $\frac{2 \rho U_{I}^{3}}{3 \pi \hat{\alpha} A^{2}}$ and noting that the average of the velocity cubed over a tidal cycle is $\overline{U^{3}}=\frac{4 U_{0}^{3}}{3 \pi}$ then the normalised power averaged over a tidal cycle is:

$$
\bar{P}_{\text {drag }}=2 \lambda_{\text {total }}\left[U_{0}\left(\lambda_{\text {total }}\right)\right]^{3}
$$

Note that the 2 ensures that the max value is equal to 1 .

Similar results may be found for the power lost due to the turbine farm and the friction drag by adjusting the value of $\lambda$ and noting that

$$
\lambda_{\text {total }}=\lambda_{0}+\lambda_{F}=\hat{\alpha}\left[\frac{L}{h} C_{D}+\frac{C_{F}}{A_{F}}\right]
$$

where $A_{F}$ is the channel cross sectional area at the farm

The power lost by the flow due to the presence of the turbines is thus

$$
\bar{P}_{\text {lost }}=\frac{4}{3 \pi} \frac{\rho C_{F}}{A^{2}} U_{0}^{3}=2\left(\lambda_{\text {total }}-\lambda_{0}\right)\left[U_{0}\left(\lambda_{\text {total }}\right)\right]^{3}
$$

This includes energy losses due to turbulence and mixing etc.

The fraction of power available for useful production is only the fraction $r_{l}$ of the power lost due to the farm. The remainder is the mixing losses. So the available power averaged over a tidal cycle is:

$$
\bar{P}_{\text {avail }}=2 r_{1}\left(\lambda_{\text {total }}-\lambda_{0}\right)\left[U_{0}\left(\lambda_{\text {total }}\right)\right]^{3}
$$

The figure above plots these three relationships. It is observed that on the green curve is a representation of equation 15 .

The actual power may be determined from the non-dimensional values by multiplying by:

$$
\frac{2 \rho U_{I}^{3}}{3 \pi \hat{\alpha} A^{2}} \text {. }
$$

As one would expect the transport $U_{0}$ decreases as the drag terms increase, thus the transport will change as more power is extracted. For the case of the tidal straight the change will be very small, but for a channel connecting open sea and a lagoon or estuary the change may be noticeable. In the figure the lower curve shows the power available against total drag, or an increase in the number of turbines. The left hand portion of the curve corresponds to a tidal straight and the right hand side a shallow channel with a range of scenarios in between. Thus increasing the number of turbines in a tidal channel generally produces more power, whilst increasing the number of turbines in a shallow channel will in some cases result in less power. This has important implications when a staged development is proposed.

The layout of a turbine farm is often dictated by other factor, such as navigation requirements. Thus it is usual to decide how far across the channel the farm will stretch. Following that it is desirable to optimise the power developed from the farm. The method for optimising settings is to compute the power available for a given value of $\varepsilon$ over a range of $r_{3}$ and optimised using a numerical search technique. The figure below shows optimal values of $r_{l}$ for various values of $\varepsilon$. 


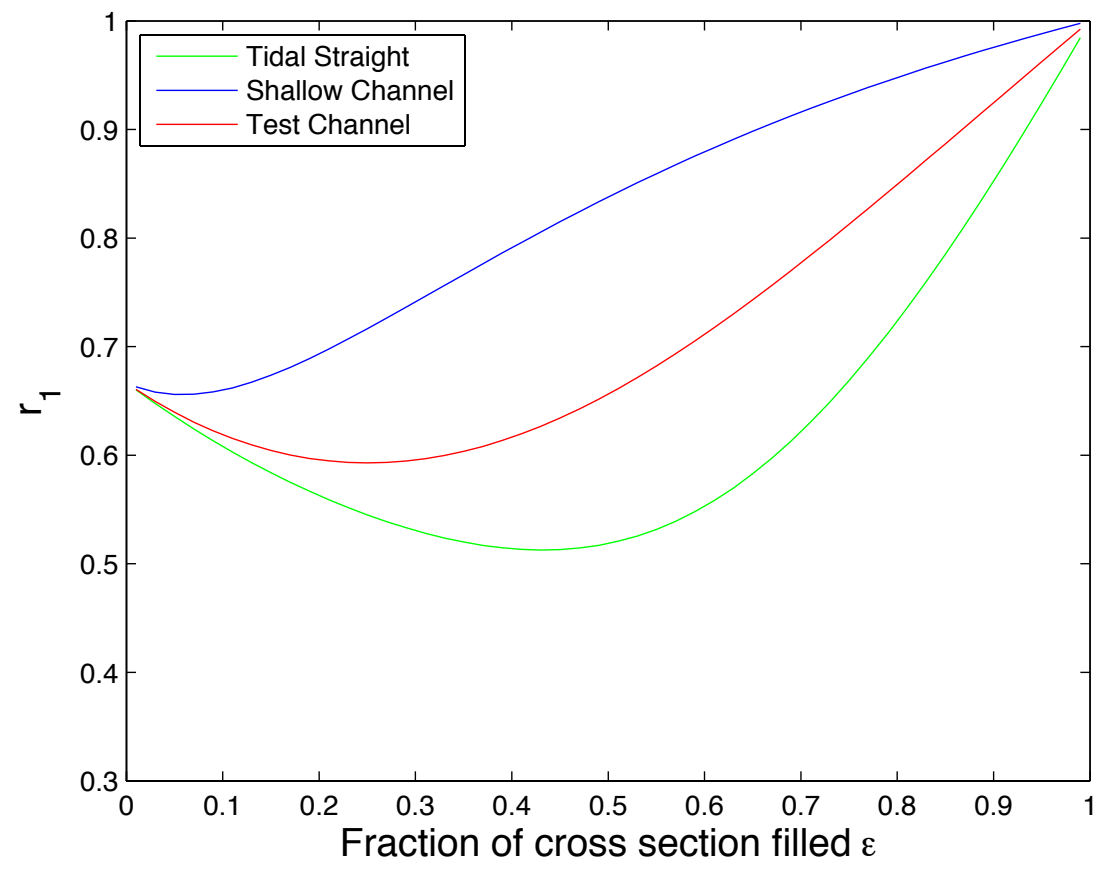

Figure 8 Optimised velocity coefficient

\section{Comparison}

The $\left(r_{l}=u_{1} / u_{0}\right)$ value for maximum power output from the finite element modelling exercise produced values in the range $0.45-0.46$. This was the flow through the actual turbine. In the case of multi turbines the value is averaged over all the turbines. Setting $r_{l}$ to 0.67 , the Betz optimum, produced less power for both cases.

The measurement of $r_{l}$ is problematic as there is flow around each turbine, which is faster than that through the turbine, as shown by the velocity plot above. The value of $r_{l}$ is close to 0.65 if the gross effect of the 20 turbines is considered. This value is obtained from the velocity contours and indicates a velocity through the turbine area of approximately $1.25 \mathrm{~m} / \mathrm{s}$. The maximum flow through any of the turbines is $1.2 \mathrm{~m} / \mathrm{s}$ and the minimum is $0.88 \mathrm{~m} / \mathrm{s}$ and the average $0.98 \mathrm{~m} / \mathrm{s}$. The undisturbed velocity is $2.0 \mathrm{~m} / \mathrm{s}$.

The analytical approach produces optimised values of $r_{l}$ for a given value of $\varepsilon$. The value for a typical channel similar to those modelled is in the approximately 0.59 for 20 turbines occupying $27 \%$ $(\varepsilon=0.27)$ of the channel $(800 \mathrm{~m}$ in a $3000 \mathrm{~m}$ wide channel). However the turbines only take up half of that width. So for $\varepsilon=0.135$; the analytical value is 0.61 . Thus one would expect a velocity of $1.2 \mathrm{~m} / \mathrm{s}$ or thereabouts through the turbine fence.

For the single turbine the analytical analysis gives 0.662 for the value of $r_{l}$, whereas the finite model produces a value closer to 0.5 actually through the turbine, but the flow adjacent to the turbine is slowed to about $1.3 \mathrm{~m} / \mathrm{s}$, which is not too much of a discrepancy.

The values of $r_{3}\left(=u_{3} / u_{0}\right)$ for the above 2 cases are 0.353 and 0.334 respectively.

\section{CONCLUSION}

The paper has presented two ways of assessing the performance of turbine farms in coastal channels. Both illustrate the need for careful planning of the turbine farm. The two methods agree on a broad basis but differ in detail. This is due to the nature of the assumptions and approximations made in each method.

There are some important differences which need to be addressed

- Analysis assumes total coverage of turbines across farm

- Actual turbines have gaps between them 
- What value of $\varepsilon$ is appropriate?

- What value of velocity to take from finite element model?

Turbine farms should be carefully planned and the layout considered carefully. In some cases the addition of turbines will lead to less power produced per turbine. The conservative approach of a staged development may not be the best way to proceed as the addition of more turbines does not always lead to an increase in power output.

\section{BIBLIOGRAPHY}

Bedard, R. (2005). Tidal in stream energy conversion (TISEC) devices. EPRI.

Betz, A. (1920). Das maximum der theoretisch möglichen ausnutzung des windes durch windmotoren. Gesamte Turbinenwesen, Heft 26.

Cummins, P. F. (2012). On the extractable power from a tidal channel. Journal of Waterway,Port, Coastal and Ocean Engineering, 138(1), 63-71.

Garrett, C., \& Cummins, P. (2005). The power potential of tidal currents in channels. Proceedings of the Royal Society A, (461), 2563-2572.

Garrett, C., \& Cummins, P. (2007). The efficiency of a turbine in a tidal channel. J Fluid Mechanics, $588,243-251$.

Lanchester, F. W. (1915). Acontribution to the theory of propulsion and the screw propeller. Trans. Inst Naval Archit, LVII(98116).

Vennell, R. (2010). Tuning turbines in a tidal channel. Journal of Fluid Mechanics, 663, 253-267.

Vennell, R. (2011a). Estimating the power potential of tidal currents and the impact of power extraction on flow speeds. Renewable Energy, 36, 3558-3565.

Vennell, R. (2011b). Tuning tidal turbines in-concert to maximise farm efficiency. Journal of Fluid Mechanics, 671, 587-604.

Vennell, R. (2012). The energetics of large tidal turbine arrays. In Press. 